\title{
Household catastrophic health expenditure and its effective factors: a case of Iran
}

\author{
Ramin Ravangard ${ }^{1,2}$, Faride Sadat Jalali ${ }^{3}$, Mohsen Bayati ${ }^{1}$, Andrew J. Palmer ${ }^{4,5}$, Abdosaleh Jafari ${ }^{*}$ (ID and \\ Peivand Bastani ${ }^{1}$
}

\begin{abstract}
Background: The World Health Organization (WHO) has placed special emphasis on protecting households from health care expenditures. Many households face catastrophic health expenditures (CHEs) from a combination of economic poverty and financing the treatment of medical conditions. The present study aimed to measure the percentage of households facing catastrophic CHEs and the factors associated with the occurrence of CHEs in Shiraz, Iran in 2018.
\end{abstract}

Methods: The present cross-sectional study was performed on 740 randomly selected households from different districts of Shiraz, Iran in 2018 using a multi-stage sampling method. Data were collected using the Persian version of the "WHO Global Health Survey" questionnaire. CHEs were defined as health expenditures exceeding $40 \%$ of households' capacity to pay. Households living below the poverty line before paying for health services were excluded from the study. The associations between the households' characteristics and facing CHEs were determined using the ChiSquare test as well as multiple logistic regression modeling in SPSS 23.0 at the significance level of 5\%.

Results: The results showed that $16.48 \%$ of studied households had faced CHEs. The higher odds of facing CHEs were observed in the households living in rented houses $(\mathrm{OR}=3.14$, $\mathrm{P}$-value $<0.001)$, households with disabled members $(\mathrm{OR}=27.98$, P-value $<0.001)$, households with children under 5 years old $(\mathrm{OR}=2.718$, P-value $=0.02)$, and those without supplementary health insurance coverage $(\mathrm{OR}=1.87$, P-value $=0.01)$.

Conclusion: CHEs may be reduced by increasing the use of supplementary health insurance coverage by individuals and households, increasing the support of the Social Security and the State Welfare Organizations for households with disabled members, developing programs such as the Integrated Child Care Programs, and setting home rental policies and housing policies for tenants.

Keywords: Catastrophic Health Expenditures, Out-of-pocket payments, Financial contribution

\section{Background}

The World Health Organization in its 2000 report has declared that one of the goals of the health systems is a fair contribution to financing healthcare expenditures [1]. A fair and equitable system is one in which households

\footnotetext{
*Correspondence: abdosaleh.jafari@gmail.com

${ }^{1}$ Health Human Resources Research Centre, School of Health

Management and Information Sciences, Shiraz University of Medical Sciences, Shiraz, Iran

Full list of author information is available at the end of the article
}

contribute to their healthcare expenditures in proportion to their affordability and income [2]. The household's financial contribution to the health system represents the financial burden imposed on the household by payments for health care [3]. Generally, part of all household incomes in societies around the world is spent on health care (ranging from $\$ 49$ in Afghanistan to $\$ 10,623$ in the United States in 2018) [4], the distribution and proportion of which may indicate the imposition of healthcarerelated financial burdens on societies [1]. original author(s) and the source, provide a link to the Creative Commons licence, and indicate if changes were made. The images or other third party material in this article are included in the article's Creative Commons licence, unless indicated otherwise in a credit line to the material. If material is not included in the article's Creative Commons licence and your intended use is not permitted by statutory regulation or exceeds the permitted use, you will need to obtain permission directly from the copyright holder. To view a copy of this licence, visit http://creativecommons.org/licenses/by/4.0/. The Creative Commons Public Domain Dedication waiver (http://creativeco mmons.org/publicdomain/zero/1.0/) applies to the data made available in this article, unless otherwise stated in a credit line to the data. 
The rising costs of health services due to the development of technologies, and the increases in individuals' health awareness and expectations have created problems in financing healthcare expenditure for people in the community [5]. Protecting people from the costs of diseases is one of the main goals of health systems [6]. Financial protection means that no household should spend more than a "reasonable proportion" of its income to finance special health services. This ratio, which includes both direct and indirect health expenditures, should not exceed the household's ability to pay, which is the result of subtracting the minimum subsistence expenditure from the total household expenses over a given period. If healthcare expenditure exceeds this level, it can lead to catastrophic health expenditures and medical impoverishment [7, 8]. Wagstaff and Doorslaer [50] have proposed two basic approaches measuring catastrophic health expenditures (CHEs). The catastrophic health expenditure in the first approach is defined as follows: direct out-of-pocket payments for health care that go beyond a certain threshold of income or household expenses. In the second approach, poverty occurs if a household is driven below the poverty line due to direct out-of-pocket payments for health) [9]. According to the World Health Organization, a household is faced with CHEs when more than $40 \%$ of its ability to pay has been spent on healthcare expenditures [10].

According to the World Health Organisation 2008 report, about 100 million people worldwide are under the poverty line each year due to health care expenditures [10]. Studies conducted in different countries have shown that the percentage of households facing CHEs varies from country to country. For instance, the results of the studies conducted by $\mathrm{Xu}$ et al. [11,12] in several countries showed that the percentage of households facing CHEs has varied from 1 to $15 \%$. In other studies carried out in Brazil and Burkina Faso, the percentage of people facing catastrophic health care expenditures was $12 \%$ and $15 \%$, respectively $[13,14]$. Meemon et al. [15] reported that the rate of facing CHEs in 2019, after the implementation of the universal health coverage plan in Thailand was $2.78 \%$, and in another study in 12 Latin American and Caribbean countries, the rates varied from 1 to $20 \%$ [16]. Similar studies have also been conducted in Iran. For example, in a systematic review, Doshmangir et al. [17] concluded that the rate of CHEs in Iran at the population level, across diseases, and among cancer patients was $4.7 \%, 24.3 \%$, and $54.5 \%$, respectively. In the study of Aryankhesal et al. (18), the overall rate of exposure to CHEs in Iran from 1984 to 2014 was reported to be $7.5 \%$ [18]. Moreover, in a study conducted by Ghiasvand et al. [19], the rates of facing catastrophic health care expenditures among rural and urban households in Iran varied from 0.5 to $14.3 \%$ and from 0.48 to $13.27 \%$, respectively.

In general, it is important to review and monitor catastrophic expenditures in health systems and to identify factors that put households at risk of facing CHEs. This will help health policy policymakers choose preventive policies and corrective measures to address this problem [2]. Estimating the rate of facing the CHEs in societies is one indicator of the performance of health systems in health resource allocation and risk distribution [20]. In Iran, whose population is mainly covered by the health insurance system, measuring the impact of health care expenditures on households plays an important role in identifying groups and communities at risk and may allow the implementation of risk reduction policies in these groups [21]. It should be noted that health insurance coverage in Iran is provided by three main organizations, including Social Health Insurance (SHI) schemes, institutional health insurance funds, and commercial health insurance organizations. SHI schemes consist of three main insurance funds, including Iran Health Insurance Organization (which covers governmental employees and all individuals that were not eligible to be covered by other health insurance organizations, with the patient co-payment of $10 \%$ and $30 \%$ for inpatient and outpatient services, respectively), Social Security Organization (which is responsible for covering workers and employees in the private sector and the self-employed persons, and provides services in its health centres and hospitals free of charge for the SSO-insured people or with the $10 \%$ and $30 \%$ patient co-payment for respectively inpatient and outpatient services in other medical centres) [22, 23], and Armed Forces Medical Services Insurance Organization (which has been established by the Ministry of Defence, covers people working in the armed forces and their families, and provides services to the insured free of charge in the military medical centres or with a patient co-payment of $10 \%$ to $35 \%$ in private medical centres with which has a contract [24]. Institutional health insurance funds such as Petroleum Industry Health Organization, the National Broadcasting Organization, banks, etc. provide insurance services to their employees. And finally, commercial health insurance organisations such as Alborz, Mellat, Pasargadae, Atiyeh Sazan Hafez, etc. provide services that basic insurers do not provide, with a patient co-payment of $30 \%$ for outpatient and $10 \%$ for inpatient services [22, 23].

On the other hand, after the implementation of the targeted subsidy plan and the occurrence of severe inflation in Iran, which resulted in major changes in the financial situation of households [25], it was necessary to study the rate of CHEs and the associated factors in the whole 
country, as well as in different regions and provinces. Iranian studies such as those by Mohammadalizadeh Hanjani and Fazaeli [26], and Nekoeimoghadam et al. [27] reported rates of CHEs of $3.90 \%$ across the whole country, and $4.10 \%$ in Kerman. However, so far no similar study has been carried out in Shiraz city in Fars province. Therefore, this study aimed to measure the percentage of households facing CHEs and associated factors in Shiraz, Iran in 2018, hoping that its findings will provide information for the health authorities and policymakers of the country and the city of Shiraz to reduce the occurrence of CHEs.

\section{Methods}

The present cross-sectional household survey was conducted in 2018. The study population included all households living in Shiraz, Iran. Shiraz is the fifth-mostpopulous city of Iran and the capital of Fars Province located in the southwest of Iran. The sample size was determined using the results of a pilot study through the use of the following formula, assuming $\alpha=0.05, d=0.04$, $\mathrm{p}=0.19, \mathrm{q}=0.81$, and design effect $=2$. households in each quintile. Health services expenditures at each quintile were calculated separately. The income and expenditures were presented based on the purchasing power parity (PPP) \$ exchange rate of 22,075 Rials per \$1 PPP according to the World Bank website [29].

In this study, the basis for estimating CHEs was the approach recommended by the World Health Organisation to investigating the fair financial contribution of households in the health system, which includes the calculation of the households facing CHEs and households driven below the poverty line as a result of health care consumption and health care expenditures (Additional file 2: Estimating CHEs) [12, 30-32].

It should be noted that households living below the poverty line before paying for health services were excluded from the study. The collected data were analyzed using SPSS 23.0 (SPSS Inc., Chicago, IL, USA), and the associations between the studied households' characteristics and facing CHEs were determined using the Chi-Square test. Then, the simultaneous associations between all studied characteristics and facing CHEs were specified using a multiple logistic regression model. A

$$
n=\frac{Z_{1-\frac{\alpha}{2}}^{2} p q}{d^{2}} \quad n=\frac{1.96^{2} \times 0.19 \times 0.81}{(0.04)^{2}}=370 \quad 370 \times 2=740
$$

where $\mathrm{n}$ is the sample size, $Z_{1-\frac{\alpha}{2}}^{2}$ is the critical value of the normal distribution at $1 r \frac{\alpha}{2}, \mathrm{p}$ is the estimated proportion of household catastrophic health expenditure, $q=1-p$, and $\mathrm{d}$ is the desired level of precision.

The determined sample size was selected using the multi-stage sampling method through the stratified sampling method proportional to size, simple and systematic random sampling methods (Additional file 1:Sampling Methods).

The data were collected using the World Health organization's questionnaire entitled "World Health survey". It was developed in 2003 to measure the performance of health systems and was translated into Persian in the study of Kavousi et al. [28], in which its availability and reliability were confirmed. The questionnaire contained the following dimensions: household socioeconomic information, household expenditures (including food, housing, education, and all other expenditures), average monthly income, demographic characteristics of each household member, the presence of disabled family members, the total household costs for outpatient services (in the previous month), and the total household costs for inpatient services (in the last 12 months).

All data collected from Shiraz households were entered into Excel version 2007, and households were classified into quantiles based on their income and the number of
P-value $<0.05$ was considered statistically significant.

\section{Results}

In the sample population, $51.50 \%$ were female, $57.60 \%$ were married, $35.76 \%$ were in the age group of $18-34$, $45.60 \%$ had academic and university degrees, $22.7 \%$ were students, $95.00 \%$ had basic health insurance coverage (95\%) especially Social Security Organization (61.18\%), and $57.88 \%$ did not have any supplementary insurance coverage (Additional file 3: Demographic characteristics of the studied sample in 2018). Of the households studied, 122 households (16.48\%) had encountered CHEs. The results of Chi-Square test showed that facing CHEs was associated with homeownership (P-value $<0.001)$, having disabled family members (P-value $<0.001$ ), and having supplementary health insurance coverage (P-value $<0.001$ ), so that out of 431 households living in the rented houses, 22\% (93 households) faced CHEs. Also, Out of 213 households with a disabled person in the family, 44\% (94 households) exposure to CHEs, and out of 338 households without supplementary insurance, $22 \%$ (76 households) faced CHEs (Table 1). It should be noted that these characteristics were associated with facing $\mathrm{CHE}$, but the association here was unadjusted.

Multiple logistic regression showed that the probability of facing CHEs in households living in rented houses was 
Table 1 Frequency of facing CHEs according to the studied household and individual's characteristics

\begin{tabular}{|c|c|c|c|c|c|}
\hline \multirow[t]{3}{*}{ Characteristics } & \multicolumn{5}{|c|}{ Facing catastrophic health expenditures } \\
\hline & \multicolumn{2}{|c|}{$\begin{array}{l}\text { Yes } \\
\mathrm{N}=122(16.49 \%)\end{array}$} & \multicolumn{2}{|c|}{$\begin{array}{l}\text { No } \\
N=618(83.51 \%)\end{array}$} & \multirow[t]{2}{*}{ P-value } \\
\hline & Frequency & Percent & Frequency & Percent & \\
\hline \multicolumn{6}{|c|}{ Household income quintile } \\
\hline First & 71 & 58.2 & 312 & 50.5 & \multirow[t]{5}{*}{0.19} \\
\hline Second & 32 & 26.2 & 222 & 35.9 & \\
\hline Third & 8 & 6.6 & 48 & 7.8 & \\
\hline Fourth & 7 & 5.7 & 20 & 3.2 & \\
\hline Fifth & 4 & 3.3 & 16 & 2.6 & \\
\hline \multicolumn{6}{|c|}{ Having a family member over 65 years of age } \\
\hline No & 11 & 9 & 63 & 10.2 & \multirow[t]{2}{*}{0.42} \\
\hline Yes & 111 & 91 & 555 & 89.8 & \\
\hline \multicolumn{6}{|c|}{ Having children under 5 years old } \\
\hline No & 21 & 14.8 & 91 & 14.7 & \multirow[t]{2}{*}{0.54} \\
\hline Yes & 121 & 85.2 & 527 & 85.3 & \\
\hline \multicolumn{6}{|l|}{ Homeownership } \\
\hline Tenant & 93 & & 338 & & \multirow[t]{2}{*}{$<0.001$} \\
\hline Owner & 29 & 23.8 & 280 & 453 & \\
\hline \multicolumn{6}{|c|}{ Having disabled family members } \\
\hline No & 28 & 23 & 499 & 78.3 & \multirow[t]{2}{*}{$<0.001$} \\
\hline Yes & 94 & 77 & 119 & 21.7 & \\
\hline \multicolumn{6}{|c|}{ Having supplementary health insurance coverage } \\
\hline No & 76 & 62.3 & 262 & 42.4 & \multirow[t]{2}{*}{$<0.001$} \\
\hline Yes & 46 & 37.7 & 356 & 57.6 & \\
\hline \multicolumn{6}{|l|}{ Household size } \\
\hline $1-2$ & 18 & 14.8 & 120 & 19.4 & \multirow[t]{3}{*}{0.75} \\
\hline $3-4$ & 83 & 68 & 352 & 57 & \\
\hline$>4$ & 21 & 17.4 & 146 & 23.6 & \\
\hline
\end{tabular}

CHEs catastrophic health expenditures

3.14 times more than homeowner ones ( $\mathrm{P}$-value $<0.001$, CI 1.84-5.35), households with disabled members 27.98 times more than those without disabled members (P-value $<0.001$, CI 6.12-32.79), households without supplementary health insurance coverage 1.87 times more than those with supplementary health insurance coverage (P-value $=0.01, \mathrm{CI} 1.18-2.96)$, and households with children under 5 years old 2.72 times more than those without 5-year-old children (P-value $=0.02$, CI 1.15 6.38) (Table 2).

\section{Discussion}

Today, with the rising costs of health care, there is growing concern about the economic impact of health spending on households facing diseases [33], so that in most political circles and parties there is a discussion about health costs and protecting households from facing CHEs [32]. The present study aimed to measure the percentage
Table 2 Estimates of the associations between studied households' characteristics and facing CHEs using the multiple logistic regression model

\begin{tabular}{|c|c|c|c|}
\hline Characteristics & Odds ratio & $\begin{array}{l}95 \% \text { confidence } \\
\text { interval }(\mathrm{Cl})\end{array}$ & P-value \\
\hline \multicolumn{4}{|l|}{ Income quintile } \\
\hline First & 1.09 & $0.35-3.38$ & 0.87 \\
\hline Second & 1.73 & $0.54-5.51$ & 0.35 \\
\hline Third & 1.50 & $0.39-5.65$ & 0.55 \\
\hline Fourth & 0.71 & $0.17-2.87$ & 0.64 \\
\hline Fifth & 1 & & \\
\hline \multicolumn{4}{|l|}{ Homeownership } \\
\hline Owner & 1 & & \\
\hline Tenant & 3.14 & $1.84-5.35$ & $<0.001$ \\
\hline \multicolumn{4}{|c|}{ Having disabled family members } \\
\hline Yes & 27.98 & $6.12-32.79$ & $<0.001$ \\
\hline No & 1 & & \\
\hline \multicolumn{4}{|c|}{ Having supplementary health insurance coverage } \\
\hline Yes & 1 & & \\
\hline No & 1.87 & $1.18-2.96$ & 0.01 \\
\hline \multicolumn{4}{|c|}{ Having a family member over 65 years of age } \\
\hline Yes & 1 & & \\
\hline No & 0.70 & $0.30-1.651$ & 0.42 \\
\hline \multicolumn{4}{|c|}{ Having children under 5 years old } \\
\hline Yes & 2.72 & $1.15-6.38$ & 0.02 \\
\hline No & 1 & & \\
\hline \multicolumn{4}{|l|}{ Household size } \\
\hline $1-2$ & 0.93 & $0.47-1.83$ & 0.84 \\
\hline $3-4$ & 0.76 & $0.41-1.41$ & 0.38 \\
\hline$>4$ & 1 & & \\
\hline
\end{tabular}

CHEs catastrophic health expenditures

of households facing CHEs and its effective factors in Shiraz, Iran in 2018.

Taking account of excluding households living below the poverty line before paying for health services from the study, the results showed that the percentage of households in Shiraz facing CHEs was $16.48 \%$, which is higher than the goal of the Sixth Development Plan of the country, i.e. reducing the rate of facing CHEs to less than $1 \%$ [34]. This large gap can be due to the increasing costs of medical services, including pharmaceutical costs and costs of using new technologies, which put a lot of upward pressure on the health expenditure, and as a result, it places a heavy financial burden on households. Another important reason could be the financing of health care in developing countries largely through out-of-pocket payments, combined with the relative lack of adequate health insurance coverage [35]. Different rates of CHEs have been reported in previous studies 
in different health systems, both in Iran and other countries. For example, in a study by Rezaei et al. [36] in 2019, $4.12 \%$ of households in western Iran were exposed to CHEs. This rate was reported $11.80 \%$ by Kavousi et al. [28], 3.14\% by Yazdi et al. [37], and 3.91\% by Ghorbanian et al. [38] in the years 1995-2015 in Iran.

Also, in Zhen et al. in China [39], the percentage of households facing CHEs was $17.50 \%$ and in the study of Barasa et al. [40] in Kenya in East Africa was 6.58\%.

The results of the multiple logistic regression in the current study showed that facing CHEs was significantly associated with living in rented houses, having disabled family members, not having supplementary health insurance coverage, and having children under 5 years old.

In other words, households living in rented houses had higher odds of facing CHEs (3.4 times) than those who owned a house, which is consistent with the results of the studies conducted by Mohammadzadeh et al. and Ghiasvand et al. [41, 42] in Iran. According to the Statistical Center of Iran, in 2018, 34\% of the budget of urban households has been spent on renting a house, which has been the highest cost among household expenditures [43]. Therefore, the costs of renting a house and transporting home appliances when moving from house to house may impose an additional burden on household income, thereby lowering households' capacity to pay for healthcare.

However, Mobaraki et al. and Khammarnia et al. [2, 44] showed there were no significant associations between homeownership and facing CHEs.

In the present study, households with disabled family members were more likely to face CHEs (27.98 times). These households are more likely to be in need of care services and, consequently, because of the high costs of care services, they have fewer financial resources to meet other family needs. Also, such households have higher direct non-medical costs, including the costs of purchasing a wheelchair, changing the home environment to adapt to the situation of the disabled person, etc. Therefore, if there is no effective protection mechanism, these households face increased risks of financial problems and catastrophic expenditures. The results of the present study are similar to those of Hatam et al. and Kavosi et al's $[28,45]$ studies in Iran. Moreover, Somkotra and Lagrada, Gotsadze et al., and Su et al. [14, 46, 47] in their studies concluded that the presence of people with physical or mental disabilities in the household could increase the household health care costs over its total costs, increasing the risk of facing CHEs.

Furthermore, there was a significant association between supplementary health insurance coverage and facing CHEs in the current study, so that households that were not covered by supplementary health insurance had higher odds of facing CHEs (1.87 times) than those covered by supplementary health insurance. It can be due to that households covered by the supplementary health insurance schemes pay less to the health system, and the supplementary health insurance organizations provide services and cover costs that basic insurers do not provide and cover. In line with the results of the present study, Mobaraki et al. [44] demonstrated a significant negative association between supplementary insurance coverage and facing CHEs. Rezapour et al. [48] showed that having health insurance coverage could protect households from facing CHEs, similar to the results of the present study. Yardim et al. and Xu et al. [11, 49] showed that having basic and supplementary health insurance coverage had a positive effect on reducing the exposure to CHEs, which are consistent with the results of the present study. However, Mobaraki et al. [44] didn't find any significant association between having basic and supplementary health insurance coverage and facing CHEs. On the other hand, the results of Wagstaff and Lindelow [50] in China showed that having health insurance coverage had increased the risk of households' exposure to CHEs by encouraging people to use more health services, especially more advanced services.

Moreover, the results of the current study showed that households with children under 5 years old were more likely to face CHEs. In other words, the higher the number of children under 5 years old in the household, the greater the risk of the financial burden on the household [51]. With the increase in the number of children under 5 years old, because of the greater need of this age group for health care and services as well as the high costs of childcare in healthy and suitable kindergarten and nursery school and buying food and dietary supplements needed by children, the households are more likely to face rising health costs and CHEs. These results are similar to those of the Mohammadzadeh et al., Sabermahani et al., and Amery et al's [4, 41, 52]. However, Hatam et al. and Kavosi et al. [28, 45] didn't show any statistically significant association between having children under 5 years old and facing CHEs.

The results of the present study showed no significant associations between facing CHEs and household income and size as well as having a family member over 65 years of age, which are consistent with the results of Soofi et al. [53] and Kavousi et al.s [28] studies, and inconsistent with those of the Mobaraki et al. [44], Emamgholipour et al. [54], Amery et al. [55], Ghiasvand et al. [42], Yardim et al. [49], Somkotra and Lagrada [56], and Su et al's [14] studies.

Overall, the reasons for the observed differences between the results of the current study and those of 
other studies mentioned can be due to the differences in the sources of data used, population and samples studied, sampling methods, data collection instruments and measuring tools used, how to determine the households' total income (for example, asking the households or the use of expenditures as a proxy), and the year of study and therefore differences in the inflation rates and out-ofpocket payments.

Like other studies, the present study had some limitations such as recall bias, self-report and lower or higher cost reporting. Also, because this study was conducted only in one city of Iran, although the fifth-most-populous one, it is necessary to be cautious in generalizing the results of the present study to other Iran cities and provinces, as well as to other similar countries.

According to the result of the current study, policymakers should pay special attention to the poor and socioeconomically disadvantaged households to reduce their exposure to CHEs in Iran through measures such as making reforms in the basic health insurance service packages, supplementary insurance premiums, cost-sharing policies, and earmarked taxes allocated to the health system.

\section{Conclusion}

According to the results of the present study, $16.48 \%$ of households in Shiraz suffered from CHEs. The results showed that households living in rented houses, having disabled family members, not having supplementary health insurance coverage, and having children under 5 years old were more likely to face CHEs. Findings indicate that the Iran health system has failed to meet the goal of the Sixth Development Plan of the country, i.e. reducing the rate of households' exposure to CHEs to less than $1 \%$. What is certain is that policymakers' attention to the factors that increase the odds of facing CHEs can help reduce such expenditures and achieve the goal of financial protection for households. National health financing systems should design policies that not only allow people to access services when needed but also reduce the risk of people facing CHEs through reducing direct and out-of-pocket payments. In the long run, the goal should be to develop prepayment mechanisms such as social health insurance, tax-based financing, or combinations of prepayment mechanisms. It should be noted that in order to achieve such mechanisms, paying attention to the political, social, and economic context is one of the main priorities [57].

According to the results of the present study and in order to decrease the risk of facing CHEs and prevent many households from exacerbating their poverty or falling below the poverty line, the following suggestions can be offered: increasing the possibility of using supplementary health insurance coverage by individuals and households; increasing the support of the Social Security and the State Welfare Organizations for households with disabled members in order to cover all or part of the costs of treatment, medical equipment and nursing services they need, as well as paying pensions to the disabled or establishing special medical centres for taking care of the disabled requiring full care; developing programs such as the Integrated Child Care Programs to reduce the mortality and disability of children under 5 years of age, improve their growth and development, and reduce the financial burden of their diseases on households; setting home rental policies and housing policies for tenants; and reforming payment systems and supervising the approved tariffs for health services.

\section{Abbreviations}

CHEs: Catastrophic Health Expenditures; PPP: Purchasing power parity; OR: Odds ratio.

\section{Supplementary Information}

The online version contains supplementary material available at https://doi. org/10.1186/s12962-021-00315-2.

Additional file 1. Sampling Methods.

Additional file 2. Estimating CHEs.

Additional file 3. Demographic characteristics of the studied sample in 2018.

\section{Acknowledgements}

The present article was extracted from the thesis written by Faride Sadat Jalali and supported financially by Shiraz University of Medical Sciences, Grant No. 1396-01-07-15831. The researchers would like to acknowledge and thank the heads of all households studied for their kind cooperation with the researchers in collecting the data.

\section{Authors' contributions}

$R R, A J, M B$, and PB conceptualized the study, conducted the analyses, and led the manuscript. FSJ, $A B$, and $M B$ collected the required data and analyzed the collected data. RR, FSJ, AJ, and AJP interpreted the data. All authors wrote the final manuscript. All authors read and approved the final manuscript.

\section{Funding}

The present article was extracted from the thesis written by Faride Sadat Jalali and supported financially by Shiraz University of Medical Sciences, Grant No. 1396-01-07-15831.

\section{Availability of data and materials}

The datasets used and/or analyzed during the current study are available from the corresponding author on reasonable request.

\section{Declarations}

\section{Ethics approval and consent to participate}

This study was approved by the Shiraz University of Medical Sciences Ethics Committee (Code: IR.SUMS.REC.1397.126), and all methods were performed in accordance with the relevant guidelines and regulations. Oral informed consent was obtained from all participants in this study and all were assured of the confidentiality of their responses. 


\section{Consent for publication \\ Not applicable.}

\section{Competing interests}

The authors declare that they have no competing interests.

\begin{abstract}
Author details
${ }^{1}$ Health Human Resources Research Centre, School of Health Management and Information Sciences, Shiraz University of Medical Sciences, Shiraz, Iran. ${ }^{2}$ Department of Health Services Management, School of Management and Medical Information Sciences, Shiraz University of Medical Sciences, Shiraz, Iran. ${ }^{3}$ Student Research Committee, Shiraz University of Medical Sciences, Shiraz, Iran. ${ }^{4}$ Menzies Institute for Medical Research, University of Tasmania, Hobart, TAS, Australia. ${ }^{5}$ Centre for Health Policy, School of Population and Global Health, University of Melbourne, Melbourne, VIC, Australia.
\end{abstract}

\section{Received: 4 March 2021 Accepted: 6 September 2021}

Published online: 16 September 2021

\section{References}

1. World Health Organization. The world health report 2000: health systems: improving performance. Geneva: World Health Organization; 2000.

2. Khammarnia M, Peyvand M, Setoodezadeh F, Barfar E, Kord Tamini A, Arefi $\cup A B$, et al. Health expenditures by households after implementation of health transformational plan: a cross-sectional study. Payesh (Health Monitor). 2018;17(3):227-37.

3. Yousefi M, Assari Arani A, Sahabi B, Kazemnejad A, Fazaeli S. The financial contribution of households using by health services. J Payavard Salamat. 2015;8(6):517-27.

4. Amery $\mathrm{H}$, Jafari A, Panahi M. Determining the rate of catastrophic health expenditure and its influential factors on families in Yazd Province. J Health Adm. 2013;16(52):51-60.

5. The World Bank. Current health expenditure per capita (current US\$). https://data.worldbank.org/indicator/SH.XPD.CHEX.PC.CD.

6. World health Organization. Fairness of financial contribution methodology. Geneva: World health Organization; 2002.

7. World Health Organization. Technical consultation on fairness of financial contribution to health systems. Geneva: World Health Organization; 2001.

8. Wagstaff A. Measuring financial protection in health, policy research working paper series 4554. Washington, D.C: The World Bank; 2008.

9. Wagstaff A, Doorslaer EV. Catastrophe and impoverishment in paying for health care: with applications to Vietnam 1993-1998. Health Econ. 2003;12(11):921-33.

10. Ekman B. Catastrophic health payments and health insurance: some counterintuitive evidence from one low-income country. Health Policy. 2007:83(2):304-13.

11. Xu K, Evans DB, Carrin G, Aguilar-Rivera AM, Musgrove P, Evans T. Protecting households from catastrophic health spending. Health Aff. 2007;26(4):972-83.

12. Xu K, Evans DB, Kawabata K, Zeramdini R, Klavus J, Murray CJ. Household catastrophic health expenditure: a multicountry analysis. Lancet. 2003;362(9378):111-7

13. Barros AJ, Bertoldi AD. Out-of-pocket health expenditure in a population covered by the family health program in Brazil. Int J Epidemiol. 2008;37(4):758-65.

14. SuTT, Kouyaté B, Flessa S. Catastrophic household expenditure for health care in a low-income society: a study from Nouna District, Burkina Faso. Bull World Health Organ. 2006;84(1):21-7.

15. Meemon N, Paek SC. The impact of Thailand's universal coverage scheme on household catastrophic health expenditure. Asia Pac Soc Sci Rev. 2019;19(3):54-144.

16. Knaul FM, Wong R, Arreola-Ornelas H, Méndez O, Bitran R, Campino AC, et al. Household catastrophic health expenditures: a comparative analysis of twelve Latin American and Caribbean Countries. Salud Pública de México. 2011;53(1):85-95.

17. Doshmangir L, Yousefi M, Hasanpoor E, Eshtiagh B, Haghparast-Bidgoli $H$. Determinants of catastrophic health expenditures in Iran: a systematic review and meta-analysis. Cost Eff Resour Alloc. 2020;18:1-21.
18. Aryankhesal A, Etemadi M, Mohseni M, Azami-Aghdash S, Nakhaei M. Catastrophic health expenditure in Iran: a review article. Iran J Public Health. 2018:47(2):166-77.

19. Ghiasvand H, Gorji HA, Maleki M, Hadian M. Catastrophic health expenditure among Iranian rural and urban households, 2013-2014. Iran Red Crescent Med J. 2015;17(9):30-9.

20. Ghiasvand H, Sha'baninejad H, Arab M, Rashidian A. Hospitalization and catastrophic medical payment: evidence from hospitals located in Tehran. Arch Iran Med. 2014;17(7):507-13.

21. Abu-Zaineh M, Mataria A, Luchini S, Moatti J-P. Equity in health care finance in Palestine: the triple effects revealed. J Health Econ. 2009:28(6):1071-80.

22. Davari M, Haycox A, Walley T. The Iranian health insurance system; past experiences, present challenges and future strategies. Iran J Public Health. 2012;41(9):1.

23. Doshmangir L, Bazyar M, Rashidian A, Gordeev VS. Iran health insurance system in transition: equity concerns and steps to achieve universal health coverage. Int J Equity Health. 2021;20(1):1-14.

24. https://www.sajclinic.com/bime-nirohay-mosalah.

25. Gudarzi R, Sabuhi M, Salarpour M, Shahnoushi N, Mehrabi H. Simulation the effect of targeted subsidies on economic growth, inflation and unemployment in Iran using stochastic optimal control algorithm (OPTCON2). Iran J Econ Res. 2013;17(53):135-57.

26. Mohammadalizadeh Hanjani $\mathrm{H}$, Fazaeli A. Equity status in Iran health system financing. Soc Welf J. 2008;5(2):289-99.

27. Nekoeimoghadam M, Akbari-Javar M, Amiresmaili M, Baneshi M, Ganjavai S. Households exposure to catastrophic health expenditures and the affecting factors in Kerman Province, Iran. J Manag Med Inform Sch. 2013;1(2):101-90.

28. Kavousi Z, Rashidian A, Pourmalek F, Majdzadeh R, Pourreza A, Mohammad K, et al. Measuring household exposure to catastrophic health care expenditures: a longitudinal study in Zone 17 of Tehran. Hakim Res J. 2009;12(2):38-47.

29. PPP conversion factor, private consumption (LCU per international \$) Iran, Islamic Rep. https://data.worldbank.org/indicator/PA.NUS.PRVT.PP? locations $=\mid \mathrm{R}$

30. Ghimire M, Ayer R, Kondo M. Cumulative incidence, distribution, and determinants of catastrophic health expenditure in Nepal: results from the living standards survey. Int J Equity Health. 2018;17(1):17-23.

31. Xu K. Distribution of health payments and catastrophic expendituresmethodology. Genebra: WHO. WHO-Discussion paper No 2; 2005

32. Yazdi-Feyzabadi V, Bahrampour M, Rashidian A, Haghdoost A-A, Javar MA, Mehrolhassani MH. Prevalence and intensity of catastrophic health care expenditures in Iran from 2008 to 2015: a study on Iranian household income and expenditure survey. Int J Equity Health. 2018;17(1):44-51.

33. Hsu J, Flores G, Evans D, Mills A, Hanson K. Measuring financial protection against catastrophic health expenditures: methodological challenges for global monitoring. Int J Equity Health. 2018;17(1):69-81.

34. Oliveira SBVD, Barroso SCC, Bicalho MAC, Reis AMM. Profile of drugs used for self-medication by elderly attended at a referral center. Einstein (São Paulo). 2018;16(4):1-7.

35. O'donnell O, Van Doorslaer E, Wagstaff A, Lindelow M. Analyzing health equity using household survey data: a guide to techniques and their implementation. 1st ed. Washington, D.C:The World Bank; 2007.

36. Rezaei S, Hajizadeh M, Ahmadi S, Sedghi S, Piroozi B, Mohamadi-Bolbanabad A, et al. Socioeconomic inequality in catastrophic healthcare expenditures in Western Iran. Int J Soc Econ. 2019;4(1):1-8.

37. Yazdi-Feyzabadi V, Mehrolhassani MH, Darvishi A. Measuring catastrophic health expenditures and its inequality: evidence from Iran's health transformation program. Health Policy Plan. 2019;34(4):316-25.

38. Ghorbanian A, Rashidian A, Lankarani KB, Kavosi Z. The prevalence and determinants of catastrophic health expenditures in Iran: a systematic review and meta-analysis. Health Scope. 2019;8(1):63-71.

39. Zhen X, Zhang H, Hu X, Gu S, Li Y, Gu Y, et al. A comparative study of catastrophic health expenditure in Zhejiang and Qinghai province, China. BMC Health Serv Res. 2018;18(1):844-51.

40. Barasa EW, Maina T, Ravishankar N. Assessing the impoverishing effects, and factors associated with the incidence of catastrophic health care payments in Kenya. Int J Equity Health. 2017;16(1):31-44. 
41. Mohammadzadeh $Y$, Hasanzadeh K. Determinants of health and the cost of catastrophic health expenses in households. J Knowl Health. 2016;11(3):8-16.

42. Ghiasvand H, Hadian M, Maleki M, Shabaninejad H. Determinants of catastrophic medical payments in hospitals affiliated to Iran University of Medical Sciences; 2009. Hakim Res J. 2010;13(3):145-54

43. Statistical Center of Iran. Summary results of the Iranian urban and rural household income and expenditure survey — the year 1397. Tehran: Office of Administrative Registers; 2019. https://www.amar.org.ir/Porta Is/0/News/1398/ch-hvd97.pdf.

44. Mobaraki H, Rezapor A, Rahiminia R, Asadi H, Ghavamiazad Z, Jooyani Y. Catastrophic health expenditure and its determinants in older adults in Tehran, Iran. Caspian J Health Res. 2018;3(3):69-74.

45. Hatam N, Orejlu PH, Jafari A, Kavosi Z. Catastrophic healthcare expenditures of hospitalized patients in the hospitals of Shiraz in 2013. Shiraz E-Med J. 2015;16(5):222-31.

46. Somkotra T, Lagrada LP. Which households are at risk of catastrophic health spending: experience in Thailand after universal coverage. Health Aff. 2009;28(3):467-78.

47. Gotsadze G, Zoidze A, Rukhadze N. Household catastrophic health expenditure: evidence from Georgia and its policy implications. BMC Health Serv Res. 2009;9(1):69-76.

48. Rezapour A, Ebadifard A, Asadi S, Bagherifaradonbeh S, Toofan F. Stimating the odd-ratio of factors affecting households' exposure to catastrophic and impoverishing health expenditures. J Mil Med. 2016;18(1):355-61.

49. Yardim MS, Cilingiroglu N, Yardim N. Catastrophic health expenditure and impoverishment in Turkey. Health Policy. 2010;94(1):26-33.

50. Wagstaff A, Lindelow M. Can insurance increase financial risk? The curious case of health insurance in China. J Health Econ. 2008:27(4):990-1005.
51. Karami M, Najafi F, Karami MB. Catastrophic health expenditures in Kermanshah, west of Iran: magnitude and distribution. J Res Health Sci. 2009;9(2):36-40.

52. Sabermahani A, Vaeze Mahdavi M, Hadian M, Asadi-Lari M. Catastrophic health expenditures and its determinants among households in Tehran in 2011, urban HEART-2 study. Razi J Med Sci. 2014;21(126):15-26.

53. Soofi M, Rashidian A, Aabolhasani F, Sari AA, Bazyar M. Measuring the exposure of households to catastrophic healthcare expenditures in Iran in 2001: the World Health Organization and the World Bank's approach. Hosp J. 2013;12(2):39-50.

54. Emamgholipour S, Akbari Sari A, Geravandi S, Mazrae H. Estimation of out-of-pocket and catastrophic expenditures among patients with cardiovascular diseases in Khuzestan. J Payavard Salamat. 2017;11(3):297-307.

55. Amery H, Vafaee H, Alizadeh H, Ghiasi A, ShamaeianRazavi N, Khalafi A. Estimates of catastrophic health care expenditures on families supported by Torbat Heydariyeh university of medical sciences in 1391. J Torbat Heydariyeh Univ Med Sci. 2013;1(2):46-54

56. Somkotra T, Lagrada LP. Which households are at risk of catastrophic health spending: experience in Thailand after universal coverage: exploring the reasons why some households still incur high levels of spending - even under universal coverage — can help policymakers devise solutions. Health Aff. 2009;28(Suppl1):w467-78.

57. Ameri $\mathrm{H}$. Equity in health financing with an emphasis on catastrophic health expenditure. Manag Strateg Health Syst. 2018;3(3):165-7.

\section{Publisher's Note}

Springer Nature remains neutral with regard to jurisdictional claims in published maps and institutional affiliations.
Ready to submit your research? Choose BMC and benefit from:

- fast, convenient online submission

- thorough peer review by experienced researchers in your field

- rapid publication on acceptance

- support for research data, including large and complex data types

- gold Open Access which fosters wider collaboration and increased citations

- maximum visibility for your research: over $100 \mathrm{M}$ website views per year

At BMC, research is always in progress.

Learn more biomedcentral.com/submissions 